\title{
Reuse of components between virtual, b-learning and face-to-face courses. A case study in Management Information Systems
}

\section{Guillermo Castilla-Alcalá}

Universidad Carlos III de Madrid, España

Email: castilla@ing.uc3m.es

ORCID:0000-0002-6694-4798

\section{Jose-Ignacio Ortíz-Gonzalez}

Universidad Carlos III de Madrid, España

Email: joortizgding.uc 3 m.es

ORCID: 0000-0002-0380-5272

\author{
Alfonso Durán-Héras \\ Universidad Carlos III de Madrid, España \\ Email: duran@ing.uc3m.es \\ ORCID: 0000-0001-8018-6391
}

\begin{abstract}
The integration between virtual and face-to-face (ftf) classroom learning is increasing. This is leading to an increase in mixed learning or blended-learning. Due to this growing trend there is a need to reuse course components between these strategies in the interest of efficiency. Additionally, the wide availability of open source software facilitates the construction of learning activities without incurring in licences expenses; activities which can then also be included in other courses. The reuse of these learning activities between virtual, $\mathrm{ftf}$ and mixed education may require significant efforts to adapt them if this possibility has not been considered in advance. Adoption of certain architectures and methodologies, that facilitate flexibility and reuse, can simplify this process, as proposed in this paper. A case study is presented on reusing learning activities on Management Information Systems (MIS) developed for either ftf instruction or for an edX MOOC, that are reused in courses in various learning modes: online, blended learning and face-to-face.
\end{abstract}

Key words: Components reutilization, b-learning, MOOC, methodology

\section{Reutilización de componentes entre cursos virtuales, presenciales y mixtos (b-learning). Un caso de estudio en Sistemas de Información Gerencial ${ }^{1}$}

\section{RESUMEN}

Cada vez es mayor la integración entre enseñanza virtual y presencial. Esto está pro-duciendo un incremento de la enseñanza mixta o blended-learning. Dada la creciente tendencia de integración de la enseñanza virtual en la formación presencial, surge la necesidad de reutilizar componentes entre dichas estrategias en interés de la eficiencia. Adicionalmente, la gran disponibilidad de software de código abierto facilita la cons-trucción de actividades docentes sin incurrir en costes de licencias, las cuales que pue-den formar parte de distintos cursos de formación. La reutilización de estas actividades docentes en la enseñanza virtual y mixta puede requerir importantes esfuerzos de adaptación de las mismas si previamente no se ha tenido en cuenta esta posibilidad en su diseño. Estas labores pueden simplificarse mediante la adopción de arquitecturas y metodologías que favorezcan la flexibilidad y la reutilización, tal como se propone en este trabajo. Adicionalmente, se presenta un caso de reutilización de actividades do-centes de un MOOC de la plataforma edX dedicado a Sistemas de Información, en el que actividades docentes son reutilizadas en otros cursos de distinta modalidad: online, híbridos y presenciales.

Palabras clave: Reutilización de componentes, b-learning, MOOC, metodología.

\footnotetext{
1 Acción financiada por la Comunidad de Madrid en el marco del convenio plurianual con la Universidad Carlos III de Madrid en su línea de Excelencia del Profesorado
}

ISSN: 0210-2773

DOI: https://doi.org/10.17811/rifie.50.1.2021.465-470 


\section{Introducción}

In this new "Digital" era, virtual learning strategies (online or e-learnig) have been popularized. This has led many higher education institutions to develop a wide variety of MOOC (Massive Open Online Course) and SPOC (Small Private Online Course).

The low completion rates of theses $100 \%$ virtual courses, fully delivered and moderated online, casts doubts on the effectivity of the e-learning strategy. Only a small percentage of the registered students finish any given MOOC course (Jordan, 2014).

Rather than replacing traditional teaching or face-to-face (ftf) classroom learning, virtual learning is becoming increasingly integrated in the $\mathrm{ftf}$ classroom and the incorporation of a greater number of electronic resources is growing (Durán et al., 2015).

It is common for $\mathrm{ftf}$ education to use online electronic resources (ICT information and Communication Technology), such as Learning Management Systems platforms (LMS) (e.g., Moodle, Sakai etc) for resource sharing (slides, lecture notes, etc.) with students, group activities (forums, group chat sessions, etc.). The percentage of utilization of online electronic resources in this learning mode is less than 25 or $30 \%$, so it is characterized as e-enhanced learning (Wenger \& Ferguson, 2006).

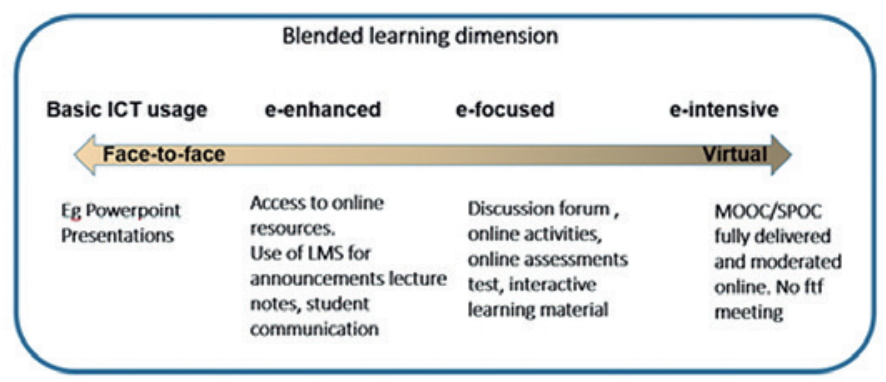

Figure 1. Learning Modalities. Adapted from (Wenger E Ferguson, 2006).

Blended learning (b-learning) is defined as the integration of both approaches: virtual and face-to-face classroom learning. Blended learning, also called hybrid learning, uses a higher percentage of online electronic resources (e-enhanced and e-focused) thus combining virtual and ftf learning (Martínez García, 2012). The most common model is the use of MOOCs in "Flipped Classroom" in which students study MOOC lessons outside of class, and interact in the ftf classroom to discuss ideas and reinforce the knowledge (Eradze et al., 2019; Pérez-sanagustín et al., 2016).

A variety of publications have shown the utility of a "blended learning" approach to enhance both the effectiveness and efficiency of learning experiences (Garrison \& Kanuka, 2004).

The development of virtual courses requires effort and dedication that can be reduced with the use of design and development methodological schemes that favour the reuse of its components in/from others virtual and blended learning courses.

This paper reviews some recommendations and advices that can be implemented to facilitate the reuse of learning components, with specific focus on cross-mode utilization, i.e., reutilizing components in a learning mode (ftf, b-learning, online...) different from that for which it was originally created. It presents a case study on reusing learning activities from both an $\mathrm{ftf}$ course and an online edX MOOC on Management Information Systems (MIS), in online, blended and face-to-face courses.

\section{Reusing course components}

After developing the course outline, and once the audience, objective, program and teaching process methodology are established, theorical o practical classes have to be developed. The components of these classes will vary depending on whether they are virtual or face-to-face classes, but in general it is possible to distinguish:

- Presentation components (Presentations/Videos): It is common to use slides created with some specific tool for presentation/video creation. These tools enable very visuals and dynamics presentation including movements and sounds Videos are mainly used for virtual courses presentations. Course concepts are explained in these videos. MOOC videos have short duration (below 10-15 minutes) and are often developed in the talking head (teacher makes a personal connection) or electronic whiteboard (the most engaging type) modes.

- Supplementary material: It is usually made up of images, audio or video, readings or complementary articles that complement the presentation material. In the case of MOOC courses, transcripts must be developed with the written script of the video, which contains the written text of everything said by the teacher in the video. Transcripts can be used for subtitles.

- Labs or complementary activities: These are practical activities where the student carries out some type of activity, be they games or simulated (or real) with educational purpose. In the case of $\mathrm{ftf}$ learning, specific infrastructure will be required and in the case of virtual learning, computer systems (local or in the cloud) with the corresponding software will be required (web, application etc). The cloud computing trend and the growing availability of open source applications enable the adaptation and sharing of open source applications in the cloud for the construction of learning activities, without incurring in extra expenses.

- Assessment activities: to evaluate the assimilation of the concepts and the evolution of the student throughout the course. These activities can cover a wide range of modalities. Questionnaires with short questions, are often used to evaluate the assimilation of concepts explained in the same class. These questions, in the case of $\mathrm{ftf}$ can be asked to students in multiple ways, either on paper or using interactive tools such as clickers or mobile apps (kahoot, wooclap etc). Self-assessment quizzes are used to assess the assimilation of concepts explained in the MOOC lesson.

Module's tests are more extensive and complex evaluations for a set of lessons. These require further analysis and reasoning to answer. In this tests, essay or project assignment can also be used. Nevertheless, the online assessment is not the most appropriate for evaluating essays or projects. Some MOOC use the peer grading review process between the students for this kind of assignments, but there is not warranty of the quality feedback and consistency between peer graders (Gamage et al., 2018).

Other than the difficulty to authenticate students' work, the main disadvantage of the online assessment is that it is limited to objective question (Mckimm et al., 2003)

The Management Information System (MIS) learning is generally two-fold: theoretical, that introduces the business and technological concepts, and practical or hands-on activities, where the student is trained to work with MIS. Practical activities are built by instructors on specific local o cloud platforms (hard \& soft), based on the creation of simulated environments and games. 
It is possible to enhance the learning experience, by replicating global business scenarios based on enterprise applications like ERPs (Enterprise Resource Planning) where students face management and decision-making problems, and they build their own knowledge about the ERP role and his utility.

It is not an easy task the design of such practical activities based on the use of information technology to enhance the learning experience. For this reason, it is convenient to design the activities contemplating the possibility of reuse in other related courses in mind.

The reuse of components is a key element in the efficiency of courses customization and adaptation to multiple learning environments.

Using content production methodologies, it is easy to reuse presentations, lab exercise or assessment activities in different courses.

Most of the virtual education components can be reused in $\mathrm{ftf}$ learning. Listed below, there are some premises and advices that facilitate component reuse:

- At least partially, most of the presentation components are largely reusable in both environments. Even short MOOC video segments can be a component of an $\mathrm{ftf}$ classroom. As a general rule, it is useful to avoid references to previous lessons in videos and presentations, avoiding local expressions or adapted to a specific audience, which hinders reutilization.

- Complementary activities based on the cloud are easily accessible from any place, so they have high potential for reuse. When using local servers, it is difficult that local servers can support an access peak load of many student simultaneously or not having security access problem into the private network of the university or institution.

- Self-contained, independent activities, that do not rely on or require completion of previous activities, are easier to reuse. If questions are considered, it is more convenient not to include them in the activity and pose the questions independently. In this way, a lab activity can be reused in different courses, and the assessment activities can be different in each one, as shown in the following case study.

- Modular, adaptable, modifiable and with adequate size to be combined. Courses are made of combined components.

- Assessment activities can be reused in different lessons and courses by using question libraries in the MOOC or LMS platform. Assessment should not be confused with grading; assigning a grade to a student's work is a different task.

\section{Case study}

This case describes the process of reusing, across disparate learning modes, hands-on activities that give students the opportunity to experience a real ERP in a business setting. A first basic hands-on activity (H1) was developed as a component within a purely online edX MOOC (Introduction to Management Information System: A survival guide), and a second, more comprehensive hands-on ( $\mathrm{H} 2)$ was initially developed for an entirely $\mathrm{ftf}$ laboratory session within a regular, for-credit MIS course "Dirección y Sistemas de Información" (DYSI) in Industrial Engineering master at Universidad Carlos III de Madrid, hereafter referred to as $u c 3 m$. Since their applicability for blended environments was apparent, both hands-on were later incorporated into other MIS courses (online, blended, $\mathrm{ftf}$ ), that were aimed at different audiences and had different learning objectives.

Both hands-on activities were laid out with the objective of providing an idea of how an ERP looks like. To do so, the student follows an individual business transaction (a customer order) throughout a representative business process (the order fulfillment process). In this process the student gets a first-hand experience of how data is shared between the different ERP modules, since the student introduces information in some modules that will then be available in others. This is because the ERP modules share a common database, as explained in the MOOC.

Both activities were designed with Odoo ERP, an open source ERP software, in the Odoo Cloud, accessible through the Internet.

1. The first $\mathrm{H} 1$ assignment was based on Odoo's online demo (https://demo.odoo.com/) which does not require the student sign up. The student accesses through the web browser to a generic instance of the Odoo ERP to execute a simple business process: vendors, products, customer quotations are created in the "Purchases" "Inventory" and "Sales" modules. In the "Manufacturing" and "Purchases" modules the student verifies that there is a "manufacturing and purchase orders", and the orders are confirmed. The student then validates the reception of the products, marks the product as done when finished and validates the delivery order to send the product to the customer in the "Inventory" module. Finally, he creates the invoice in the "Sales" module. If the student does not finish the activity in one attempt he will have to start again from the beginning because no partial result is saved. This activity was initially developed for the edX MOOC.

2. The second assignment $\mathrm{H} 2$ was based on the Odoo education program program (Odoo SA, 2020), which requires the student to sign up in order to access the Odoo ERP business management system of a fictitious company, tailored by the instructor, that manufactures and markets beer. This activity involves a more comprehensive order fulfilment process (including accounting) and it is substantially longer. Each student has access to his own instance of the Odoo ERP in the Cloud for 4 hours, and if the student completes the registration form, he could access this instance later (up to 9 months) and proceed with the activity. This activity was initially developed as a ftf activity for a lab session.

We shall now describe how these activities are included and reused in virtual, blended and $\mathrm{ftf}$ courses.

- Virtual: MOOC: Introduction to Management Information Systems: A Survival Guide.

This is a course in the edX platform which focuses on what MIS are and on their role in today's organizations, offered both in English and in Spanish. The course is designed for a massive audience (between 5 and 10 thousand students per edition), so, the assessment is fully automatized through a question library.

The MOOC format is self-paced. It is structured in six "modules" or "weeks". This means that the MOOC's videos, self-assessment quizzes, recommended readings, as well as the graded activities, are available from the start of the course.

The course initially included the $\mathrm{H} 1$ hands-on activity explained above as a "hands-on assignment" in Week 4. For the Spanish version (since it its used as an optional activity in the DYSI course, see below), but not for the English version, H1 was later replaced by the more comprehensive $\mathrm{H} 2$ after trimming it down and stripping it from components requiring co-location, e.g. those using licensed software. Every assignment has his own assessment activity of 5 random questions based on different libraries of questions included in the MOOC platform. The assessment represents the $10 \%$ of the course grade.

\section{- Mostly virtual: SPOC: EVE (European Virtual Exchange) course}

In the EVE project, european students have the opportunity to take university courses with credit recognition without physically 


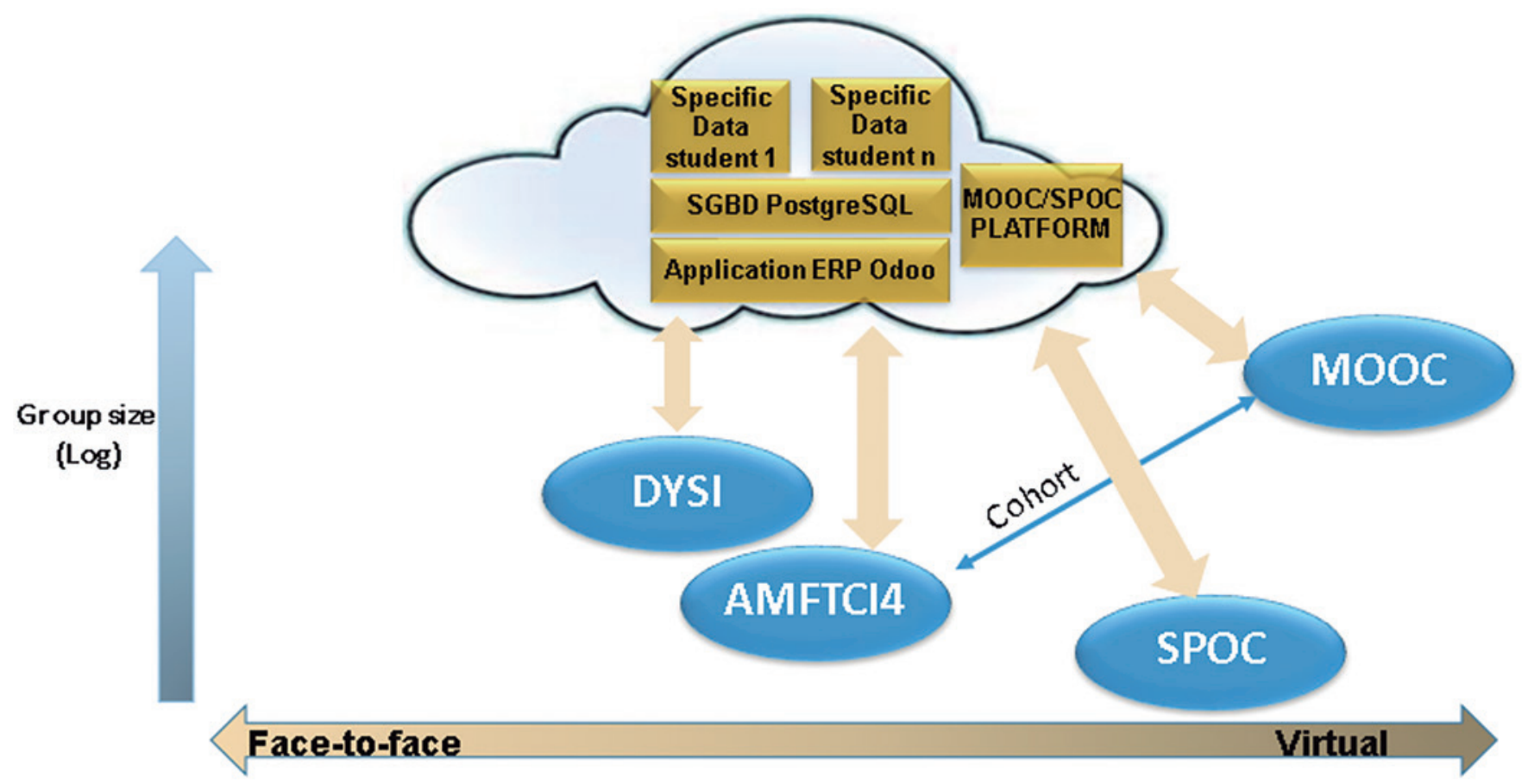

Figure 2. Reuse of learning activities by multiple courses: $f t f$, virtual and blended

leaving their home universities. Most learning take place online; however, it includes proctored exams held in the student's own university.

This SPOC is an online course hosted in the private SPOC platform of $u c 3 m$, also based on Open edX, including the same learning materials and hands-on activities as the abovementioned MOOC. In that course, the assessment activities are different since there is credit recognition associated with the course completion. Thus, the main components of the SPOC course are the same as in the MOOC, however assessment and grading are different. The SPOC format is also self-paced. Graded activities, however (endof-week tests and assignments), are made available only progressively, according to the schedule shown in the SPOC. Students must complete these graded activities within the time window assigned to each of them.

In this case the two hands-on activities are mandatory for students in order to ensure a learning experience that meet the stated objectives. The SPOC grade and the second hands-on activity grade represent half of the credit recognition, the other half is based on $\mathrm{ftf}$ evaluation. The remote students must perform an additional $\mathrm{ftf}$ evaluation exam in order to demonstrate the acquired knowledge (Kursun, 2016).

- Blended: Advanced Management Frameworks and Tools in Connected Industry 4.0 Master-AMFTCI4 ( $f t f)$.

This is an english-medium blended course within the Connected Industry Master of $u c 3 m$. The goal is that students know how to apply and integrate the knowledge acquired and to foster their ability to solve problems and make judgments in new and complex environments. Students from this course attend a series of face-to-face, instructor-led lectures and case discussion sessions. Additionally, they register in the edX MOOC (English version), and are enrolled in a special subgroup called cohort. They thus undertake H1 like any other MOOC user; additionally, the trimmed-down, online $\mathrm{H} 2$ assignment and the corresponding assessment activities are made available only to this cohort.

- Mostly ftf: Management and Information Systems-DYSI

This is a spanish, $\mathrm{ftf}$, instructor-led course within the master in Industrial Engineering at $u c 3 m$ which provides full professional accreditation. Lab session includes the $\mathrm{ftf}$, unabridged $\mathrm{H} 2$ assignment. Complementarily and voluntarily, students are encouraged to undertake the spanish version of the MOOC described above (including the $\mathrm{H} 1$ hands-on), and to upload in the LMS a certificate with the MOOC grade, to verify MOOC completion. An additional assessment with specific questions on this hands-on is included in the final $\mathrm{ftf}$ examination.

Figure 2 depicts the four courses positioned within the dual dimensions of size of the student groups (log scale) and $\mathrm{ftf}$ vs virtual learning.

\section{Conclusions}

Some recommendations that facilitate the reuse of learning activities in $\mathrm{ftf}$, virtual and blended courses, particularly between courses based on different learning modes, have been discussed, thereby increasing the efficiency of the course production process. A multi-mode case analysis has been used to illustrate the approach feasibility and potential contribution, even when courses involved span heterogeneous learning environments, student bodies and learning objectives.

\section{References}

Durán, R., Estay-niculcar, C., \& Álvarez, H. (2015). Adopción de buenas prácticas en la educación virtual en la educación superior. Aula Abierta, 43(2), 77-86. https://doi.org/10.1016/j. aula.2015.01.001 
Eradze, M., Urrutia, M., Reda, V., \& Kerr, R. (2019). Blended Learning with MOOCs. From Investment Effort to Success: A Systematic Literature Review on Empirical Evidence. Proceeding of the European MOOCs Stakeholders Summit, EMOOCs.

Gamage, D., Whiting, M., Perera, I., \& Fernando, S. (2018). Improving Feedback and Discussion in MOOC Peer Assessement Using Introduced Peers. In IEEE (Ed.), 2018 IEEE International Conference on Teaching, Assessment, and Learning for Engeneering.

Garrison, D. R., \& Kanuka, H. (2004). Blended learning : Uncovering its transformative potential in higher education. The Internet and Higher Education, 7, 95-105. https://doi.org/10.1016/j. iheduc.2004.02.001

Jordan, K. (2014). Initial Trends in Enrolment and Completion of Massive Open Online Courses. The International Review of Research in Open and Distance Learning, 1(15), 133-159.

Kursun, E. (2016). Does Formal Credit Work for MOOC-Like Learning Environments? International Review of Research in Open and Distrtibuted Learning, 17(3).
Martínez García, F. (2012). Impact of the proliferation of information and technology in Higher Education. Aula Abierta, 40, 97-106.

Mckimm, J., Jollie, C., \& Cantillon, P. (2003). ABC of learning and teaching - Web based learning. BMJ, 326(April), 870-873. https://doi.org/10.1136/bmj.326.7394.870

Odoo SA. (2020). Odoo education program. https://www.odoo.com/ es_ES/page/education-program

Pérez-sanagustín, M., Hilliger, I., Alario-, C., Kloos, C. D., \& Rayyan, S. (2016). Describing MOOC-based Hybrid initiatives: The H-MOOC Framework. Proceeding of the European MOOC Stakeholder Summit, February, 1-13.

Wenger, M. S., \& Ferguson, C. (2006). A Learning Ecology Model For Blended Learning from Sun Microsystems. In C. J. Bonk \& C. R. Graham (Eds.), Handbook of blended learning: Global Perspectives, local designs. Pfeiffer Publishing. 
